\title{
Model Studies on the Synthesis of Madangamine Alkaloids. Assembly of the Macrocyclic Rings
}

\section{Stefano Proto, Mercedes Amat, "Maria Pérez, Roberto Ballette, Federica Romagnoli, Andrea Mancinelli, and Joan Bosch}

Laboratory of Organic Chemistry, Faculty of Pharmacy, and Institute of Biomedicine (IBUB), University of Barcelona, 08028-Barcelona, Spain

amat@ub.edu

Received Date (will be automatically inserted after manuscript is accepted)

\section{ABSTRACT}

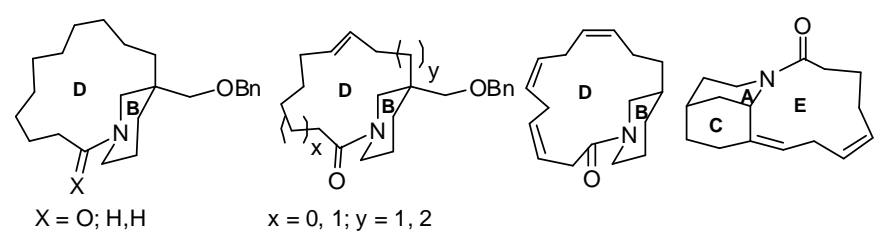

Using simplified model derivatives, the assembly of the macrocyclic rings of madangamines, including the 13- and 14-membered $D$ rings of madangamines $C-E$, the all-cis-triunsaturated 15-membered $D$ ring of madangamine $A$, and the (Z,Z)-unsaturated 11-membered $E$ ring common to madangamines $A-E$, has been studied.

The marine sponges belonging to the order Haplosclerida are a source of numerous polycyclic alkaloids with a variety of skeletal structures (manzamines, sarains, nakadomarin A, ingenamines, madangamines, among others), which share a common biogenetic origin from oligomeric macrocycles bearing a partially reduced 3-alkylpyridine moiety. ${ }^{1}$

In particular, madangamines (Figure 1) possess an unprecedented diazatricyclic core (rings A-C) and two macrocyclic rings connecting N-7 with C-9 (ring D) and $\mathrm{N}-1$ with $\mathrm{C}-3$ (ring E). ${ }^{2}$ Although significant in vitro cytotoxicity against a number of cancer cell lines has been

(a) Andersen, R. J.; van Soest, R. W. M.; Kong, F. In Alkaloids: Chemical and Biological Perspectives; Pelletier, S. W., Ed.; Pergamon: Oxford, U. K., 1996; Vol. 10, pp 301-355; (b) Berlinck, R. G. S. Top Heterocycl. Chem. 2007, 10, 211-238; (c) Kornprobst, J.-M. In Encyclopedia of Marine Natural Products; Wiley:Weinheim, 2010, Vol. 2, pp 683-723.

2 Isolation: (a) Kong, F.; Andersen, R. J.; Allen, T. M. J. Am. Chem. Soc. 1994, 116, 6007-6008; (b) Kong, F.; Graziani, E. I.; Andersen, R. J. J. Nat. Prod. 1998, 61, 267-271; (c) de Oliveira, J. H. H. L.; Nascimento, A. M.; Kossuga, M. H.; Cavalcanti, B. C.; Pessoa, C. O.;

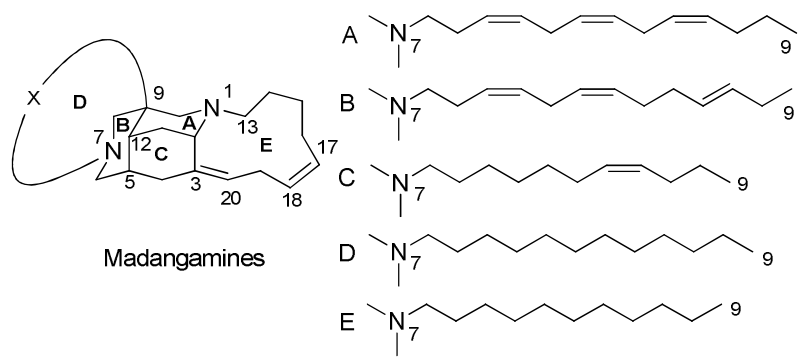

Figure 1. Madangamine alkaloids

reported for some members of this series, further pharmaceutical research on these alkaloids has been hampered by the low quantities of available samples. As

Moraes, M. O.; Macedo, M. L.; Ferreira, A. G.; Hajdu, E.; Pinheiro, U. S.; Berlinck, R. G. S. J. Nat. Prod. 2007, 70, 538-543. 
no total syntheses of madangamine alkaloids have been reported to date, ${ }^{3}$ the development of synthetic routes to madangamines or synthetic analogs remains a challenging goal.

In previous work $^{4}$ we have reported a synthetic sequence for the enantioselective assembly of the advanced diazatricyclic intermediates $\mathbf{A}$ and $\mathbf{B}$ en route to madangamines, bearing rings $\mathrm{ABC}$ with the appropriate substitution and functionality to construct the macrocyclic $\mathrm{D}$ and $\mathrm{E}$ rings of these alkaloids (Figure 2).

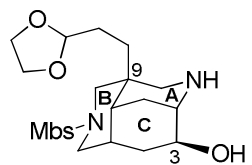

A

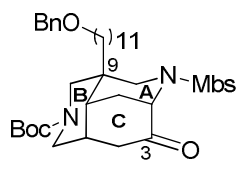

Figure 2. Advanced enantiopure diazatricyclic intermediates en route to madangamines

In this letter we report the construction of saturated and (poly)unsaturated 13-, 14-, and 15-membered rings (the western $\mathrm{D}$ ring of madangamines) as well as the $(Z, Z)$ unsaturated 11-membered $\mathrm{E}$ ring common to madangamines A-E.

As model systems for the closure of the D ring we used substituted piperidines 1-3 (Figure 3), which would allow us to perform macrocyclization reactions by reductive amination or lactamization (from $\mathbf{1}$ and $\mathbf{3}$ ), or by ringclosing olefin metathesis (from 2).
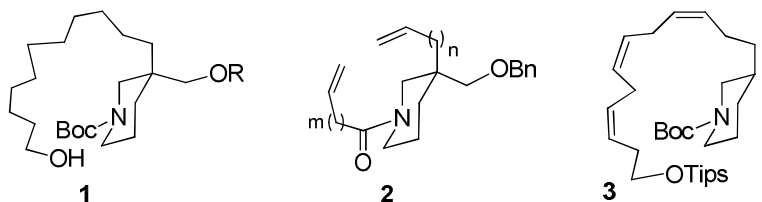

Figure 3. Model systems

Alcohols 1, bearing the eleven-carbon chain required to build up the 14-membered $\mathrm{D}$ ring of madangamine $\mathrm{D}$, were prepared from $N$-Boc valerolactam, as outlined in

3 For previous racemic syntheses of the diazatricyclic core of madangamines, see: (a) Matzanke, N.; Gregg, R. J.; Weinreb, S. M. J. Org. Chem. 1997, 62, 1920-1921; (b) Yamazaki, N.; Kusanagi, T.; Kibayashi, C. Tetrahedron Lett. 2004, 45, 6509-6512; (c) Yoshimura, Y.; Kusanagi, T.; Kibayashi, C.; Yamazaki, N.; Aoyagi, S. Heterocycles 2008, 75, 1329-1354; (d) Tong, H. M.; Martin, M.-T.; Chiaroni, A.; Bénéchie, M.; Marazano, C. Org. Lett. 2005, 7, 2437-2440; (e) Quirante, J.; Paloma, L.; Diaba, F.; Vila, X.; Bonjoch, J. J. Org. Chem. 2008, 73, 768-771.

${ }^{4}$ Amat, M.; Pérez, M.; Proto, S.; Gatti, T.; Bosch, J. Chem. Eur. J. 2010, 16, 9438-9441.
Scheme 1. Initial attempts to perform the macrocyclization by lactamization of carboxylic acid $\mathbf{4}$, generated by PDC oxidation of $\mathbf{1}$, were not satisfactory as dimer 6 was the only isolable product. When the reaction was conducted under high dilution conditions, the desired bicyclic lactam 5 was formed in acceptable yield. Alternatively, Dess-Martin oxidation of 1a, followed by $\mathrm{N}$-deprotection of the resulting aldehyde 7 and reductive amination under diluted conditions, satisfactorily led to the azabicyclic derivative $\mathbf{8}$ in acceptable overall yield.

Scheme 1. Model Annulation Studies. The Macrocyclic D Ring of Madangamine D

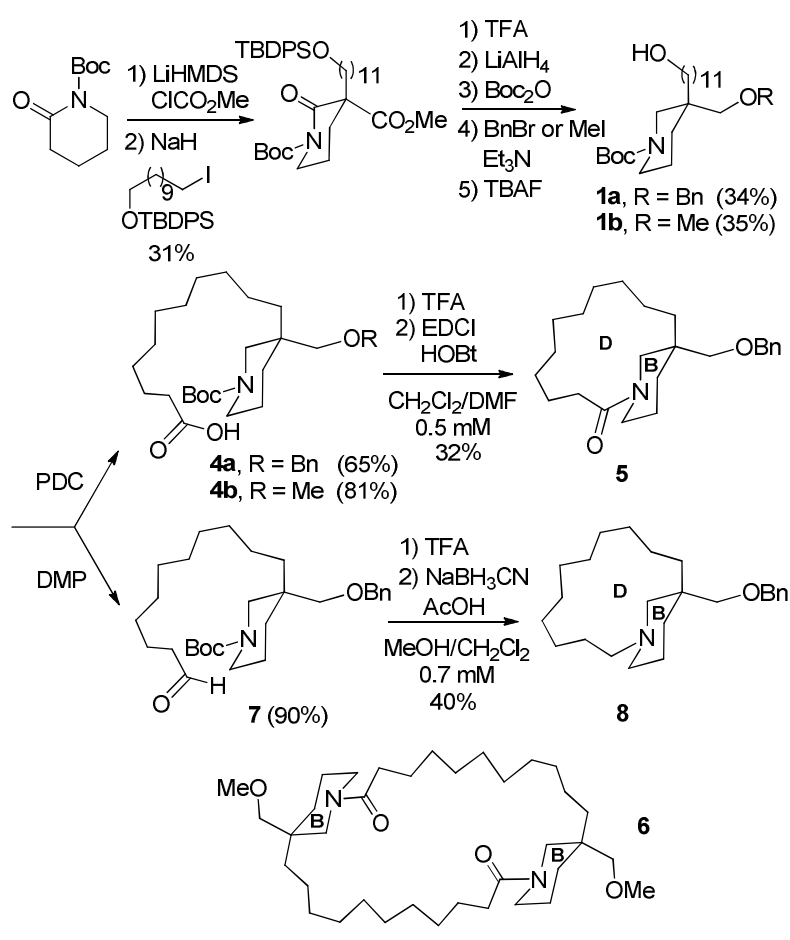

We then focused our attention on macroannulations involving ring-closing metathesis reactions. ${ }^{5}$ The required dienes $\mathbf{2}$, bearing unsaturated chains of different length, were prepared from 3-methoxycarbonyl-2-piperidone by successive $C$-alkylation and $N$-acylation reactions, as outlined in Scheme 2. Gratifyingly, diene 2a underwent a ring-closing metathesis reaction on treatment with the second-generation Grubbs catalyst, leading to the 14membered $(E)$-unsaturated lactam 9a in excellent yield. ${ }^{6}$ Cyclization of dienes $\mathbf{2 b}$ and $\mathbf{2 c}$ to the corresponding 13-

\footnotetext{
${ }^{5}$ For reviews on the construction of macrocyclic rings by $\mathrm{RCM}$ reactions, see: (a) Meng, Q.; Hesse, M. Top. Curr. Chem. 1991, 161, 109-176; (b) Deiters, A.; Martin, S. F. Chem. Rev. 2004, 104, 21992238; (c) Nicolaou, K. C.; Bulger, P. G.; Sarlah, D. Angew. Chem. Int. Ed. 2005, 44, 4490-4527; (d) Gradillas, A.; Pérez-Castells, J. Angew. Chem. Int. Ed. 2006, 45, 6068-6101.

${ }^{6}$ Only trace amounts of the $Z$-isomer in compound 9 a were detected by ${ }^{1} \mathrm{H}$ NMR.
} 
membered ring alkenes $9 \mathbf{b}$ and $9 \mathbf{c}$ were also satisfactory, although the yields were lower. ${ }^{7}$

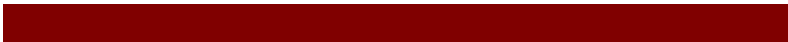

Scheme 2. Model Annulation Studies. Construction of the Macrocyclic D Rings of madangamines C, D, and E by RingClosing Metathesis
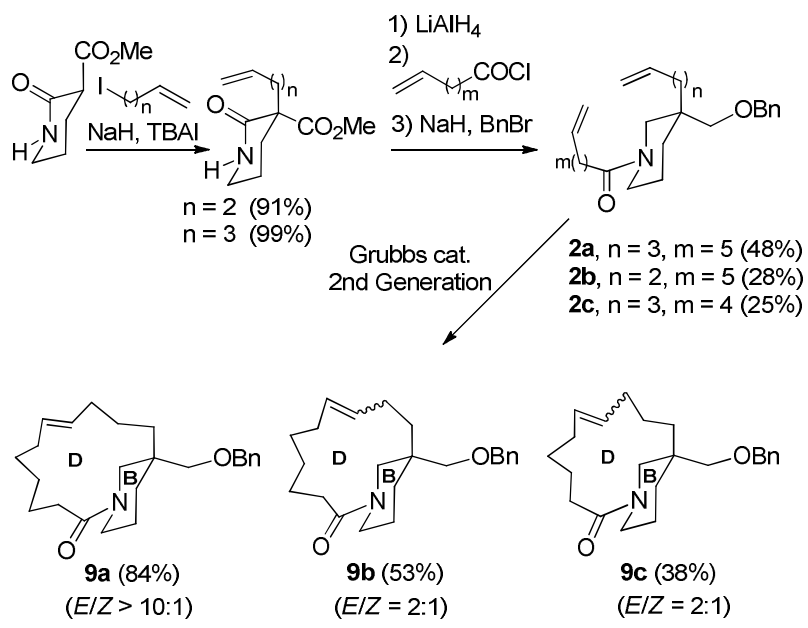

Having achieved model macrocyclizations to construct 13- and 14-membered rings, like those present in madangamines $\mathrm{C}-\mathrm{E}$, we then explored the construction of the skipped (Z,Z,Z)-unsaturated 15-membered ring characteristic of madangamine $\mathrm{A}$. The required twelvecarbon chain was installed sequentially, by $C$-alkylation of $\delta$-valerolactam with 4-iodo-1-(trimethylsilyl)but-1-yne ${ }^{8}$ followed by cuprous iodide-catalyzed coupling of the

Scheme 3. Model Annulation Studies. Construction of the Macrocyclic D Ring of Madangamine A
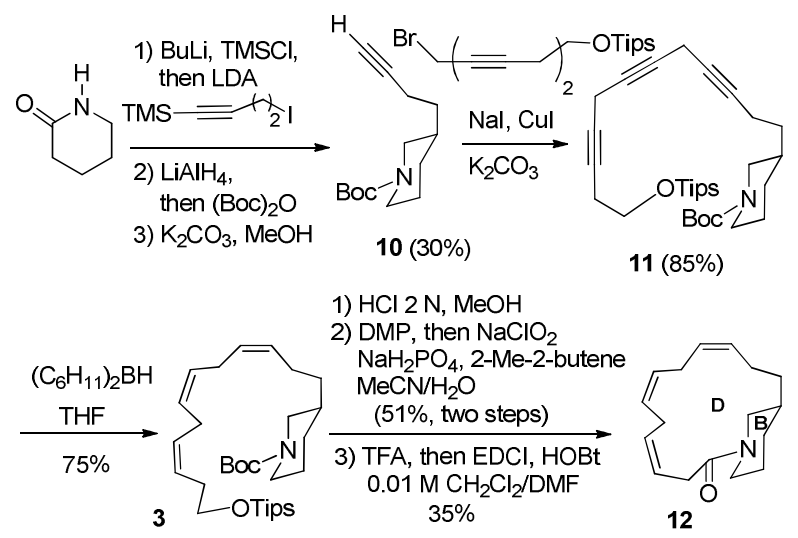

${ }^{7} \mathrm{E} / \mathrm{Z}$ mixtures of isomers (2:1 ratio) were formed in these reactions. In the cyclization of $\mathbf{2 b}$, the corresponding dimer was isolated in $12 \%$ yield.

${ }^{8}$ Dutheuil, G.; Webster, M. P.; Worthington, P. A.; Aggarwal, V. K. Angew. Chem. Int. Ed. 2009, 48, 6317-6319 terminal alkyne $\mathbf{1 0}$ with 8-bromo-1(triisopropylsilyloxy)octa-3,6-diyne. ${ }^{9}$ Reduction of the resulting triyne $\mathbf{1 1}$ with dicyclohexylborane ${ }^{10}$ stereselectively provided the unstable all-cis model triene 3. In this series the final annulation to $\mathbf{1 2}$ was performed by macrolactamization, as outlined in Scheme 3.

To study how to assemble the $(Z, Z)$-unsaturated 11membered eastern $\mathrm{E}$ ring of madangamines A-E, we used azabicyclic ketones 14, which embody rings $\mathrm{A}$ and $\mathrm{C}$ of the alkaloids and mimic our advanced diazatricyclic intermediate B. These model 8-oxomorphan derivatives 14 were prepared from 4-vinylcyclohexene by a straightforward route involving the generation of azide 13, epoxidation of the cyclohexene double bond, and a Staudinger reduction of the azide functionality (Scheme 4). The initially formed amino epoxide underwent a smooth in situ cyclization, directly leading to an intermediate amino alcohol, which was then $N$-protected and oxidized.

Scheme 4. Synthesis of the Model Azabicyclic Ketones 14
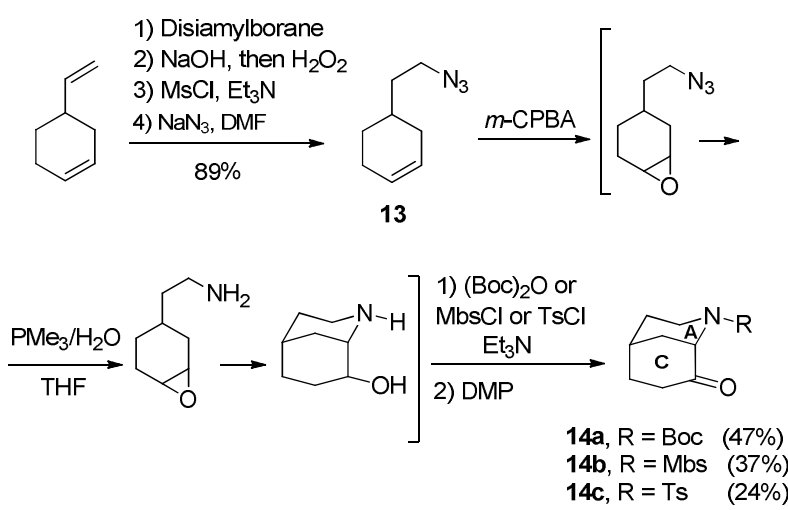

Hoping to stereoselectively install the exocyclic $Z$ double bond characteristic of madangamines A-E, we initially used the Still-Gennari modification ${ }^{11}$ of the Horner-Wadsworth-Emmons reaction, a protocol that has been employed ${ }^{12}$ with excellent $Z$ stereoselectivity from a related 8-oxomorphan derivative (Scheme 5). However, disappointingly, all attempts to induce the same stereoselectivity from ketones $\mathbf{1 4 a}$ and $\mathbf{1 4 b}$, either under the original ${ }^{12}$ or slightly modified ${ }^{13}$ reaction conditions, resulted in the generation of $Z / E$ mixtures of alkenes $\mathbf{1 5}$,

\footnotetext{
${ }^{9}$ Gueugnot, S.; Aiami, M.; Linstrumeile, G.; Mambu, L.; Petit, Y.; Larchevêque, M. Tetrahedron 1996, 52, 6635-6646.

${ }^{10}$ For a review on the construction of $(Z, Z)$ skipped 1,4-dienes, see: Durand, S., Parrain, J.-L.; Santelli, M. J. Chem. Soc., Perkin Trans I, 2000, 253-273.

${ }^{11}$ Still, W. C.; Gennari, C. Tetrahedron Lett. 1983, 24, 4405-4408.

${ }_{12}$ Yoshimura, Y.; Inoue, J.; Yamazaki, N.; Aoyagi, S.; Kibayashi, C. Tetrahedron Lett. 2006, 47, 3489-3492.

13 Blanchette, M. A.; Choy, W.; Davis, J. T.; Essenfeld, A. P.; Masamune, S.; Roush, W. R.; Sakai T. Tetrahedron Lett. 1984, 25 , 2183-2186.
} 
in which the undesired $E$-isomer was predominant (35:65 ratio).

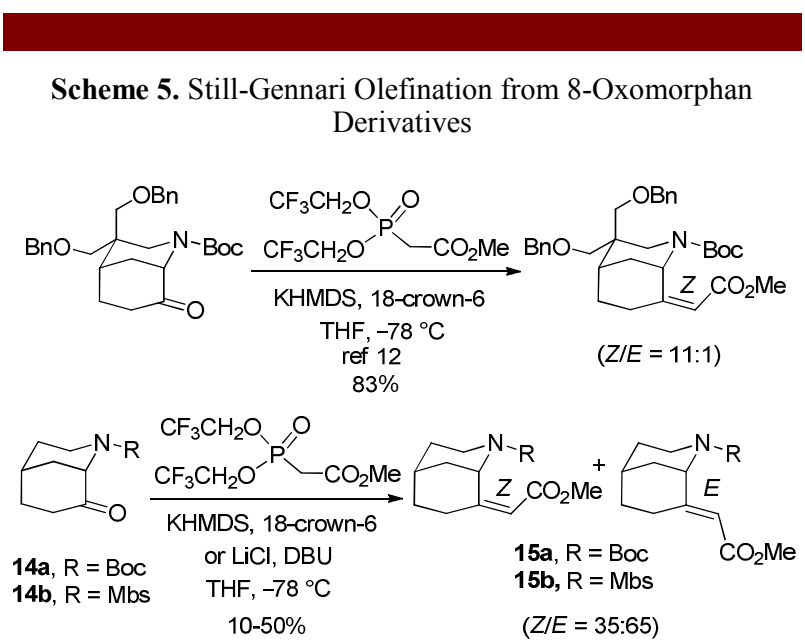

At this point, we reasoned that the use of a nonstabilized ylide could reverse the stereoselectivity of the Wittig reaction, leading to the required $Z$-isomer. ${ }^{14}$ Additionally, we envisaged a more direct approach using a eight-carbon phosphonium salt, such as $\mathbf{1 6}$ (Scheme 6), already containing the central $Z \mathrm{C}_{17}-\mathrm{C}_{18}$ double bond present in the $\mathrm{E}$ ring of madangamines and the ester functionality required for the final macrolactamization. After some experimentation, to our delight, treatment of bicyclic ketone $\mathbf{1 4 c}$ with the ylide generated from

Scheme 6. Model Annulation Studies. Straightforward Assembly of the Macrocyclic E Ring of Madangamines A-E

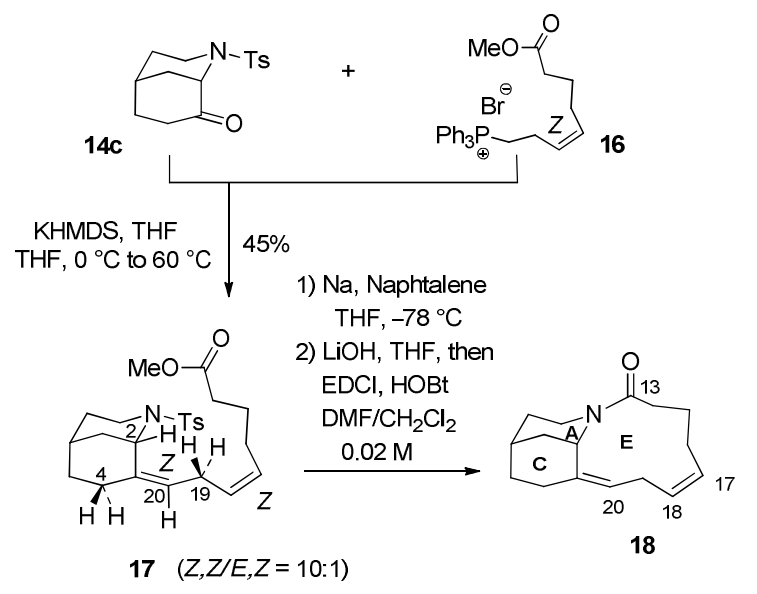

\footnotetext{
${ }^{14}$ (a) Vedejs, E.; Cabaj, J.; Peterson, M. J. J. Org. Chem. 1993, 58, 6509-6512; For a review on Wittig reaction, see: (b) Vedejs, E.; Peterson, M. J. Top. Stereochem. 1994, 21, 1-157.
}

phosphonium bromide $\mathbf{1 6}^{15}$ and KHMDS in THF $(0.75$ M) under strictly anhydrous conditions led to a highly enriched mixture $(Z / E, 10: 1$ ratio) of alkenes 17 in $45 \%$ yield. The desired $Z$ stereochemistry for the major product was deduced by a 2D NOESY experiment, which showed two sharp cross-peaks resulting from the spatial interactions between $\mathrm{H}-4 / \mathrm{H}-20$ and $\mathrm{H}-2 / \mathrm{H}-19$. After removal of the protecting tosyl substituent, alkaline hydrolysis followed by macrolactamization of the resulting crude amino acid provided a single tricyclic lactam 18, bearing the $(Z, Z)$-unsaturated elevenmembered ring of the target alkaloids.

In summary, using appropriate simplified model derivatives, we have developed synthetic routes to construct the 13- and 14-membered D rings of madangamines C-E, the all-cis-triunsaturated 15membered $\mathrm{D}$ ring of madangamine $\mathrm{A}$, and the $(Z, Z)$ unsaturated 11-membered $\mathrm{E}$ ring common to madangamines A-E.

Acknowledgment Financial support from the MICINN, Spain (Project CTQ2009-07021/BQU), and the AGAUR, Generalitat de Catalunya (Grant 2009-SGR1111 ) is gratefully acknowledged. Thanks are also due to the Ministry of Education (Spain) for a fellowship to R.B and to the Leonardo da Vinci programme (Unipharma Graduates-6 and 7) for mobility grants to F.R. and A.M., respectively.

Supporting Information Available Full experimental and ${ }^{1} \mathrm{H}$ and ${ }^{13} \mathrm{C}$ NMR description of new compounds. ${ }^{1} \mathrm{H}$ NMR spectra for compounds 1-5, and 7-14c, and 16-18; ${ }^{13} \mathrm{C}$ NMR spectra for compounds $2,3,9-14 c$, and 16,17 ; mass spectra for compounds $\mathbf{5}, \mathbf{8}, \mathbf{1 8}$. This material is available free of charge via the Internet at http://pubs.acs.org.

\footnotetext{
15 The synthesis of the phosphonium salt 16 was accomplished by modification of known procedures: (a) Zamboni, R.; Milette, S.; Rokach, J. Tetrahedron Lett. 1983, 24, 4899-4902; (b) Wang, S. S.; Rokach, J.; Powell, W. S.; Dekle, C.; Feinmark, S. J. Tetrahedron Lett, 1994, 35, 4051-4054; (c) Sandri, J.; Viala, J. J. Org. Chem. 1995, 60, $6627-6630$.
} 